\title{
SOCIO- ECONOMIC FACTORS OF POVERTY OCCURRENCE AND WAYS OF ITS REDUCTION
}

\author{
Hamdamov Sh.I. \\ ${ }^{1}$ Hamdamov Shahzod Ilxom ogli - 1st year Doctoral Student, Institute of Forecasting and \\ Macroeconomic Research, Tashkent, Uzbekistan
}

Article DOI: https://doi.org/10.36713/epra8288

DOI No: 10.36713/epra8288

\begin{abstract}
Based on the degree of development of the problem, the main goal of this study is the specifically disclosed essence and main directions of Uzbekistan's strategy to reduce the poverty level of the population. In this regard, this study has the following goals: based on a comprehensive analysis of sources, literature and practical experience, to reveal the essence of the problem of poverty, to show the socio-political, spiritual factors and prerequisites, the reasons for its "existence in the conditions of sovereign Uzbekistan; to show the influence and social consequences poverty on the deterioration of the living standards of the population of Uzbekistan; to study the place, role and significance of the strategy of the Government of Uzbekistan to reduce poverty of the population of villages and cities of the republic; to find out the nature and characteristics of the level of poverty among various categories of the population of Uzbekistan; to give a comprehensive description of the problem of poverty, to show the patterns and logic of its appearance, scientifically substantiate the main ways and possibilities of the most effective solution.

Proceeding from the set goals, in the course of the study, an attempt was made to solve the following tasks: to study the main socio-political factors contributing to an increase in poverty among the population and to show the features of its social consequences on the deterioration of people's living standards; to generalize and systematize various scientific approaches and methods concerning the impact of the strategy of the Government of Uzbekistan to reduce and overcome poverty among the population of the republic; to give a specific analysis of the program settings of the main political institutions and the state's concern for raising the standard of living and reducing poverty among the population of Uzbekistan; show objective and subjective difficulties, contradictory and conflict situations in the process of implementing Uzbekistan's strategy to reduce poverty among the population of the republic.
\end{abstract}

KEYWORDS. Formation of the national criterion of poverty: specific characteristics, existing experience.

\section{INTRODUCTION}

Among the topical problems of modern theory and practice of economic and political sciences, one of the leading places is occupied by the issue of "poverty". Therefore, the study and analysis of this problem today is acquiring great scientific, theoretical and practical importance. According to historical experience, the problem of "poverty" has always been and remains the focus of attention of any people, nation and state. Analysis of sources and scientific literature indicate that the emergence and existence of poverty is associated primarily with the uneven distribution of material and spiritual benefits among members of society $[1,2]$.

As a result, society is divided into classes, poor and rich people. In this regard, the study of this problem becomes very relevant and special attention is paid to it by scientists from all over the world, the CIS countries, including the Republic of Uzbekistan.
Taking into account the requirements of today, scientists have developed various concepts and put forward many points of view on the issue of poverty reduction. Special attention was paid to the disclosure of the essence, social, economic and political causes of the emergence and factors of persistence of poverty and its social consequences in modern conditions.

Poverty issues were analyzed in the historicalpsychological, socio-economic, philosophical and legal, religious aspects and from a political point of view.

The problem of poverty is still the subject of lively discussions. The range of problems associated with the study of the problem of poverty is very wide and varied. These include, in particular, issues related to sources, the nature of the direction, social change in the transition from traditional to modern society; from the technological backwardness of countries, especially the difficult living standard of the 
population, which is insufficiently provided with material and spiritual benefits [3, 4]. Thus, the urgency of the problem solved within the framework of the study is due to:

- Firstly, the urgent need to develop theoretical and methodological foundations for studying the new economic situation in the post-Soviet space in the study of the economic and socio-political reasons for the emergence and persistence of poverty among the population;

- Secondly, the sharp exacerbation of sub-ethnic relations in Uzbekistan in the 90s of the XX century, a decrease and a shortage of material benefits, led to an increase in poverty among the population. Study of the causes and conditions that determine the emergence of the last search for poverty mechanisms, their overcoming and prevention;

- Thirdly, the research of the topic has not yet been the subject of a special, comprehensive analysis, which determined the choice of the research topic;

- Fourthly, an important point that determines the relevance of the problem under study is the place, role and significance of Uzbekistan's strategy to reduce poverty among the population of Uzbekistan. Under the new conditions, the government of the republic is making an attempt to find effective means and ways to reduce the level of poverty among the population $[5,6]$.

Fifthly, one of the most serious problems facing the population of Uzbekistan is the increase in poverty. In Uzbekistan, as in other countries with economies in transition, this problem is explored in separate articles, brochures and reports. However, they lack an analysis of how growing poverty affects the situation of people, what is its impact on their health, education, labor activity, and the situation in the family. Based on this, it should be noted that the study and analysis of the features of the manifestation of poverty in the conditions of sovereign Uzbekistan in the light of the strategy of the Government of the republic to reduce poverty, the study of the main ways and methods of combating the problem of poverty in modern conditions is particularly relevant. The named factors determine the extreme urgency of the problem under study.

\section{LITERATURE REVIEW AND PROBLE M STATEMENT}

The problem of poverty chosen for the study is interdisciplinary in nature. Its disclosure is hardly possible without turning to research in the field of philosophy, history, law, cultural studies, sociology, political science, social psychology, political economy, demography, ecology and other sciences. The multidimensional nature of the dissertation problems prompts to take into account the achievements contained in the works of scientists from the CIS countries, Uzbekistan and abroad. In recent years, a large number of monographs, collective works, brochures and articles have been published on the theory and practice of the problem of poverty, where an analysis of the social essence, the causes of poverty and its consequences in society is given. In the works of such famous scientists of the CIS countries as: Olopade, B. C., Okodua, H., Oladosun, M., \& Asaleye, A. J. (2019), Magombeyi, M. T., \& Odhiambo, N. M. (2017), Rewilak, J. (2017), Miyamoto, M. (2020), Liu, Q. Q., Yu, M., \& Wang, X. L. (2015), Ahmad, F., Draz, M. U., Su, L., Ozturk, I., Rauf, A., \& Ali, S. (2019) and others consider the socio-political, economic and spiritual factors of the emergence of poverty in society and its social consequences on the deterioration of the living standards of the population. At the same time, the work of these scientists revealed general issues of the complex relationship between poverty and food security in society. They scientifically substantiated the general regularity of the process of the emergence and manifestation of the problem of poverty among the population. A significant contribution to the study of the problem of poverty, its place and social consequences in society was made by famous scientists: L.S. Rzhanitsina, E.Khatkina, E. Mezentseva, L.M. Prokofieva, P.Festin, O.Muracheva, I.E. Kalabikhina, G.Nzharelova, M.Malisheva and others. These authors specifically and in detail stated their points of view on this problem, revealed the causes and factors of the emergence of poverty in society, substantiated the ways and methods of overcoming it. The essence and social consequences of poverty in society were studied at a sufficient level. However, in the writings of these scientists there is no definition of the concept of poverty. Despite this, they certainly provided some research assistance in researching the problem of poverty in Uzbekistan. Scientists of Uzbekistan made a significant contribution and research and generalization of the experience of the Government of the republic on problems of poverty among the population. The works of Durmanov, A., Umarov, S., Rakhimova, K., Khodjimukhamedova, S., Akhmedov, A., \& Mirzayev, S. (2021), Nurimbetov, T., Umarov, S., Khafizova, Z., Bayjanov, S., Nazarbaev, O., Mirkurbanova, R., Durmanov, A. (2021), Nazarova F., Sangirova U., Abdurazakova N, Beknazarov Z. (2020), Horbach L., Hilorme T., Nazarova F., Andriichenko N. (2020), Umarov S., Durmanov A., Li M., Khushvaktova K., Yakubova K., Shanasirova N. (2021), Umarov S., Yusupov E., Yakubova S., Saipova M., Mamasadikov A., Khamrayeva S., Durmanov A. (2021), Turdieva M.U. (2020) and a number of others are very valuable [7, $8,9]$. However, the task of these authors did not include a special study of the problem of the topic of 
our dissertation. In their writings, they dealt with certain aspects of the problem of poverty in Uzbekistan. A more specific and detailed description of the problem of poverty and its reduction among the population of Uzbekistan is reflected in the works of the President of the country Sh. Mirziyoyev.

It should be noted that despite the presence of a number of works in this direction, it has not yet been thoroughly researched in Uzbekistan. Based on this, it is not possible to fully consider a complex set of issues related to natural and contradictory processes of the emergence and manifestation of the level of poverty on the example of Uzbekistan within the framework of one work. Understanding the complexity of the problem under study, the author does not claim to provide an exhaustive disclosure of this phenomenon [10]. This task can be solved only by joint efforts of representatives of various sciences and entire scientific teams. In the work, based on the analysis of all of the above, taken in the aggregate of sources and literature, an attempt was made to study the features of manifestation, socio-political and spiritual factors of increasing and decreasing the level of poverty among the population of the Republic of Uzbekistan, the strategy of the Government of the republic to reduce the level of poverty in modern conditions. All these and other questions that require theoretical and practical comprehension determined the choice of the topic, determined the goals and objectives of the study.

\section{THE AIM AND OBJECTIVE S OF THE STUDY}

Based on the degree of development of the problem, the main goal of this study is the specifically disclosed essence and main directions of Uzbekistan's strategy to reduce the poverty level of the population. In this regard, the following objectives have been set for this study:

- on the basis of a comprehensive analysis of sources, literature and practical experience, reveal the essence of the problem of poverty, show the socio-political, spiritual factors and prerequisites, the reasons for its "existence in the conditions of sovereign Uzbekistan;
- To show the influence and social consequences of poverty on the deterioration of the living standards of the population of Uzbekistan;

-To find out the nature and characteristics of the level of poverty among various categories of the population of Uzbekistan;

- To give a comprehensive description of the problem of poverty, to show the patterns and logic of its appearance, to scientifically substantiate the main ways and possibilities of the most effective solution.

\section{MATERIALS AND METHODS}

The methodological basis of the study is the dialectical principles, laws, interrelation and interdependence of socio-political processes arising from the strategy of Uzbekistan to reduce poverty among the population of the republic. The main provisions and conclusions are contained in many works of leading Uzbek and foreign scientists covering this problem. Along with this, the formulation and scientific analysis of a number of new theoretical problems open up additional opportunities for a deeper study of the specifics of the problem of poverty and conflict situations in Uzbekistan. In the course of the research, we used systemic, logical, sociological, structural and functional methods of analysis, as well as a comparison method. We believe that this study will help develop a unified methodology for accounting and assessing those objective conditions that determine the characteristics of the current state of the problem of poverty and conflicts among the population of sovereign Uzbekistan [11].

\section{RESULTS OF EXPERIMENTAL STUDIES}

The poor part of the population not only does not benefit from the rapid economic growth characteristic of the country, but it is itself unable to contribute to the development of society due to limited access to main markets, said an employee of the Center for Economic Research and Reforms.

Table 1. Foreign model of poverty reduction

\begin{tabular}{|l|l|}
\hline \multicolumn{1}{|c|}{ People's Republic of China } & \multicolumn{1}{c|}{ United States of America } \\
\hline $\begin{array}{l}\text { Minimal consumption costs were accepted as the } \\
\text { criterion of poverty. The daily required income is 7-8 } \\
\text { yuan or \$ 1.2. The government uses this criterion to } \\
\text { determine the level of poverty. But this criterion is not } \\
\text { related to the social protection system. }\end{array}$ & $\begin{array}{l}\text { The minimum cost is calculated on the basis of } \\
\text { different households. For example, the poverty line for } \\
\text { a family of three is } \$ 20,780 \text { a year, } \$ 2,140 \text { for a } \\
\text { single person, and } \$ 33,740 \text { for a family of six. These } \\
\text { numbers are used as a measure of poverty in almost all } \\
\text { states. }\end{array}$ \\
\hline \multicolumn{1}{|c|}{ Russian Federation } & \multicolumn{1}{c|}{ Commonwealth of Independent States } \\
\hline $\begin{array}{l}\text { From 2021, there has been a shift from the absolute } \\
\text { method of determining the poverty criterion to the } \\
\text { ratio method. According to him, the subsistence } \\
\text { minimum is set at } 44.2 \% \text { of median income. }\end{array}$ & $\begin{array}{l}\text { The calculation of the minimum subsistence minimum } \\
\text { and the value of the minimum consumer basket is } \\
\text { based on the normative method, the minimum need for } \\
\text { food, non-food, services. }\end{array}$ \\
\hline
\end{tabular}


The current poverty line in Uzbekistan has been limited to 2,100 kcal per day since 2000, based on a proposal from the World Bank. The lower part of the border is considered poor [12].

On the basis of this criterion, the annual poverty rate is determined by a survey of households $(10,000$ respondents) conducted by the State Statistics Committee. (In 2020, the poverty rate will be $8.3 \%$ ). Poverty detection by this criterion is relatively complex, has a high error rate, non-food products and services are not taken into account, and has limited application in practice. The level of poverty defined by this limit is mainly used by international organizations and research institutes in the preparation of reports. In official practice, these criteria are not used in the development of measures to reduce poverty [13].

Advantages and disadvantages of foreign and Uzbek experience, taking into account the specifics of the country, it is possible to suggest the following directions for determining the national criterion of poverty:

- Determining the value of the minimum consumption expenditures proposed by the World Bank through a selective sociological survey, which is radically improved and meets international standards.

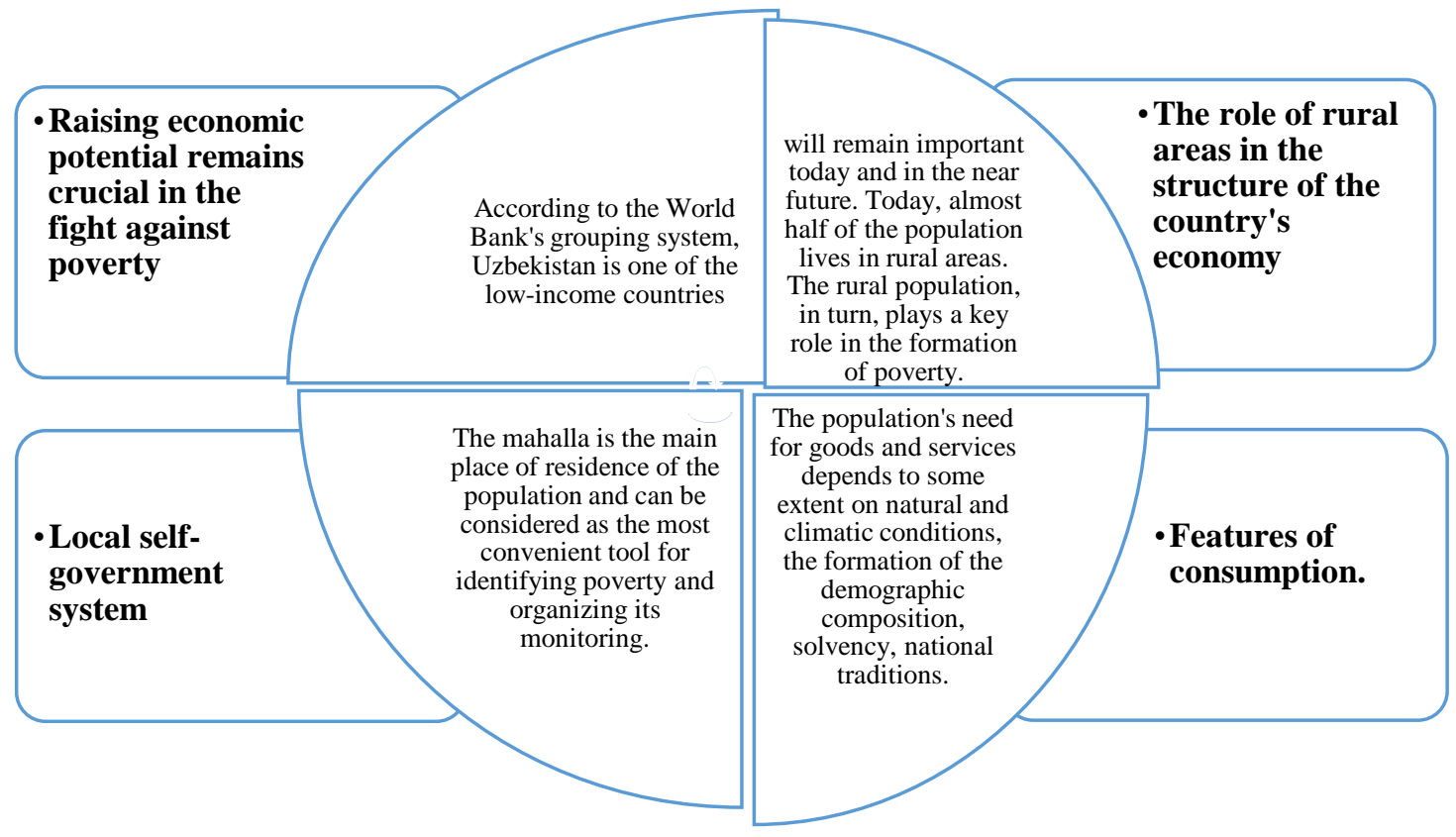

Figure 1. Matrix system and ways to reduce poverty

- Declaring $70.0 \%$ of the officially announced minimum wage (747.3 thousand) in 2021 as a national criterion. Gradually increase the value of this criterion to 100.0 percent over three years and equate it to the official minimum wage.

- Determining the value of the real minimum consumption expenditures based on the results of a specially prepared surveys of low-income families directly across all communities, taking into account the specifics of the country, the measures currently being taken to reduce poverty [14].

\section{DISCUSSION OF EXPERIMENTAL RESULTS}

In the context of the crisis caused by the coronavirus pandemic, poverty is one of the global and intractable problems of the modern world. It has a negative impact, both on the quality of life of the population, and on the social, economic and political side of the functioning of any state.

Among the main causes of poverty are: economic (unemployment, lack of jobs, low income, insufficient funding of social programs); social (disability, old age, poor health, single-parent families, a large number of dependents in the family, belonging to a minority of a particular ethnic group, low qualifications); political (military conflicts, disintegration of the country, forced migration).

The poverty level is not clearly defined and depends on the general level of well-being of the country. At the same time, a distinction is made between absolute and relative poverty. Absolute poverty implies the inability of a person to meet his basic basic needs - food, clothing, housing. Relative poverty is due to the lack of inadequacy of the means 
to lead a lifestyle that is common or widely accepted in a given society. It includes good nutrition, normal conditions for life, work and rest, education and medical services. The level of relative poverty is set in comparison with the average disposable income in the country.

The negative consequences of poverty for the socio-economic development of society and the state are manifested in the following: 1) economic growth is constrained; 2) increasing social tension in society; 3) the crime rate is increasing; 4) migration processes are activated; 5) the lifestyle of the population is deteriorating. Poverty can also be viewed as one of the negative factors affecting demographic and, therefore, national security. There is also a psychological aspect of poverty: it causes a feeling of shame in a person, worsens his psychological state, humiliates his dignity and selfesteem.

The desire by any means to resolve the problem of poverty should be a natural priority for any modern civilized state and for the entire world community. Therefore, the problem of poverty is central to the global UN documents - the Millennium Declaration (2000-2015) and the 2030 Agenda for Sustainable Development, which has been implemented since 2015 .

In developing their programs and projects, the World Bank, UNDP, FAO, UNICEF and other international organizations also prioritize the problem of poverty reduction. According to the World Bank, 736 million people (about $\mathbf{1 0} \%$ of the world's population) live in extreme poverty (with an income below \$ 1.9 a day). Almost half of the world's population - $\mathbf{3 . 4}$ billion people live on less than $\$ \mathbf{5 . 5 0}$ a day, that is, they are relatively poor. Due to the impact of the COVID-19 pandemic, localized conflicts and climate change, an additional 88 to $\mathbf{1 1 5}$ million people are projected to end up in extreme poverty.

The President of the Republic of Uzbekistan Shavkat Mirziyoyev sets the long-term strategic goal of his policy to ensure sustainable and comprehensive economic growth, increase per capita income, reduce poverty and inequality.

It is known that the issue of poverty in our country has been a closed topic for many years. In his Address to the Oliy Majlis on January 24, 2020, the head of our state spoke openly on this issue and for the first time poverty reduction was identified as a state political task. According to preliminary calculations, the poor population in the country is $\mathbf{1 2}$ $\mathbf{1 5}$ percent, or 4-5 million people.

An open statement and recognition of this problem by the President testifies to his special attention to pursuing a strong social policy, where the vital interests of the people, their needs and problems are at the forefront, as well as the readiness of the head of state to take full responsibility for their solution.

The experience of China is indicative. Considering that Uzbekistan is at the initial stage of formation and development of comprehensive approaches to overcoming poverty, it is extremely important to study international experience in combating poverty, implement best practices, methods and solutions, taking into account the specifics of the country.

In order to establish international cooperation and exchange experience in combating poverty, the head of our state calls for expanding cooperation at the global level. In his speech at the 75th anniversary session of the UN General Assembly, Shavkat Mirziyoyev proposed to identify the topic of combating poverty as one of the main ones, as well as to organize a Global Summit dedicated to this problem.

Within the framework of the SCO, he initiated the establishment of a mechanism for meetings of the heads of ministers and departments of the member states responsible for poverty reduction, and the development of a cooperation program to support those in need of help.

To date, the most noteworthy and revealing experience in the fight against poverty is that of China. The country is implementing the world's most ambitious poverty alleviation program, the social policy of the Chinese authorities is aimed at transitioning in the near future to a society of harmonious development and average prosperity.

According to estimates of the World Bank, b uduchi world's largest country in terms of population, China has done a great job of reducing poverty and achieved remarkable results. In more than 40 years of reform and opening-up policies, more than $\mathbf{8 0 0}$ million rural residents have lifted themselves out of poverty, and the poverty rate fell from $\mathbf{9 7 . 5} \%$ in 1978 to $\mathbf{0 . 6} \%$ at the end of 2019 , accounting for $\mathbf{7 0} \%$ of the global contribution to the fight poverty.

On February 25, 2021, Chinese leader Xi Jinping, speaking at a meeting dedicated to the country's achievements in eliminating poverty, said that China had won a victory in the fight against absolute poverty. 98.99 million people in rural areas were lifted out of poverty, 832 counties and 128 thousand villages were removed from the poor areas. Over the past eight years, China has invested $\$ \mathbf{2 4 6}$ billion in povertyalleviation.

China's success in the fight against poverty was largely ensured by the provision of social support to the poor, providing them with employment and 
employment. For these purposes, the following were carried out: reforms in agriculture, construction of infrastructure, support for private entrepreneurship, increasing the availability of education and medical services. In all these areas, targeted measures and targeted programs were adopted, where the emphasis was on the development of rural areas.

At the same time, the practice of directing and securing employees of the central state apparatus and business representatives to poor villages, stimulating the influx of personnel into the countryside, and organizing training for the rural population has shown particular efficiency.

Taking into account the advanced experience of China in the fight against poverty, Uzbekistan aims to cooperate with Beijing in this direction. At the beginning of 2021 between the Ministry of Economic Development and Poverty Reduction in Uzbekistan and Chinese $m$ nternational Center for poverty reduction have been reached agreement on signing the interagency Memorandum on cooperation in the fight against poverty and the adoption of a plan of joint practical measures for the coming years.

Formation of an Uzbek Model for Poverty Reduction - First Steps

Having studied the experience of foreign countries, especially China, in the fight against poverty, as well as based on a huge amount of information about the difficulties of the population, obtained through the direct dialogue with the people organized by the President through virtual receptions, the country's leadership began a large-scale systematic work to develop a policy and form its own Uzbek models in the field of poverty reduction.

Responsible state structures were established separately and special positions were created in the system of state power. In particular, the Ministry of Economic Development and Poverty Reduction was created, the post of Deputy Prime Minister for Financial and Economic Affairs and Poverty Reduction was introduced. In the system of state authorities and local self-government, responsibilities have been distributed vertically and positions have been created responsible for reducing poverty at the level of makhalla, district, city, region.

Active work is underway to develop a methodology for defining the concept of poverty, criteria and methods for its assessment. Together with international organizations (UN, World Bank) and leading experts, the Concept and Strategy for Poverty Reduction, the National Strategy for Social Protection of the Population for 2021-2030 are being developed. On February 17, 2021, by order of the President, the Concept of the National Strategy for Social Protection of the Population for
2021-2030 was approved, which provides for the simplification of the process of receiving social benefits. From March 2021, the minimum consumer spending of the population will be announced.

At the same time, the creation of a list of families in need - "iron notebook" ("temir daftar"), became the basis for organizing work to provide unified social support and prevent the risk of vulnerable segments of the population who found themselves below the poverty line during the pandemic.

On the basis of household visits to families, an "iron notebook" was created in each mahalla, which includes 7 categories of families in need of material assistance and support: 1) low-income; 2) families with people with disabilities; 3) family, Mr. Oujda social protection; 4) lonely elderly people; 5 ) citizens who are constantly unemployed; 6 ) citizens who have been unemployed due to quarantine; 7) people who returned from epidemiologically disadvantaged regions.

Officials must report in their daily work on the lists of the "iron notebook" in electronic form on the site sakhovat.argos.uz. By the end of the year, at least one person should be employed in each family included in the "iron notebook".

The main essence of the formation of the "iron notebook" is that it allows: firstly, to more accurately identify those who really need help, to analyze and identify the real situation with poverty on the ground. Secondly, to systematize data on the problems and needs of the needy segments of the population.

Third, based on the analysis of problems, develop targeted targeted measures to provide assistance to vulnerable groups of the population. These measures are reflected as clear tasks, over the implementation of which strict state control is established. Until the specific problem of each family included in the "iron notebook" is resolved, this family will not be removed from the list.

So, according to the data of the Ministry of Economic Development and Poverty Reduction in 2020, 592,586 families were included in the "iron notebook". Of these, as a result of the measures taken, $456 \quad 659$ families were subsequently withdrawn, 614290 people were employed.

In contrast to the classical approach, when citizens themselves turn to the state for help, in the approach to the formation of the "iron notebook" the method of "social diagnosis" of the situation of the population is applied - when the state itself goes to citizens who find themselves in a difficult situation, identifies their problems, studies the reasons for them. appearance. Taking into account the interests 
and proposals of citizens, individual programs are developed to solve these problems.

"Iron notebook" served as the basis for the introduction in 2020 of a new mechanism of "Unified Register of Social Protection», which contains all the information for the needy families and allows them to provide more than $\mathbf{3 0}$ types of social services in electronic form. This mechanism makes it possible to simplify the process of applying for social benefits to those in need (to reduce the number of certificates and supporting documents) and the system for considering these applications.

It is noteworthy that with the help of the "iron notebook" problems are not only determined, but they are also systematized. For example, there is a distribution of the list of problems that are solved at the level of the district or region, as well as a category of issues, the solution of which is provided at the republican level.

Moreover, based on the analysis of the identified problems, specific measures are developed that are included in district and regional programs of socio-economic development. At the national level, targeted programs are being developed, such as "Obod kishlok", "Obod mahalla" and a number of others. At the same time, district and regional programs are submitted to the local Kengashes of People's Deputies, which conduct their own monitoring and periodically hear reports on them from the heads of local authorities. Thus, parliamentary and public control over the solution of these problems was established.

Thus, the "iron notebook", introduced at the initiative of the President, has already yielded great results, becoming the basis for organizing planned systematic work to provide targeted social protection through the following measures:

1) Organization of targeted social support. A new procedure for working with the most vulnerable and low-income segments of the population (women, youth, children, the elderly, the disabled) has been determined: in the context of each mahalla, the socalled "youth notebook" and "women's notebook" are formed. Particular attention is paid to young people and women in need of social, legal and psychological support, as well as seeking to acquire new knowledge and profession.

A new system of special support for children (from low-income families, orphans, disabled people) and the elderly is being created.

In 2021, it is planned to create a Public Fund for Supporting Children (with a budget of $\mathbf{1 0 0}$ billion soums). $\mathbf{5 0}$ billion soums will be allocated from the state budget to provide housing for 900 orphans. To provide assistance to the elderly on a permanent basis, the financial capabilities of the republican fund " Nuroniy " will be expanded. For these purposes, the fund will be allocated 100 billion soums.

2) Providing employment for the population. In 2021, it is planned to allocate $\mathbf{5 0 0}$ billion soums from funds for promoting employment and public works to ensure employment of the needy segments of the population. Today, among women, the unemployment rate is $\mathbf{1 5}$ percent, among young people - $\mathbf{1 7}$ percent. Therefore, the government has set a priority task to provide employment for unemployed youth and women through training them in demanded professions and entrepreneurship, followed by financial support for setting up a business.

In 2021, it is planned to create more than a thousand vocational training centers in makhallas. More than 1 trillion soums will be allocated from the budget to support women's business projects and to solve the problems of women identified on the ground.

The Concept for the development of state youth policy in Uzbekistan until 2025 and a roadmap for its implementation in 2021-2022 were adopted, which provides for the allocation of grant funds for innovative, practical and promising youth startup projects, vocational training for unemployed youth within the framework of programs "Youth: $1+$ $1 "$, as well as the introduction of the mentoring tradition under the new system.

To support the employment of the rural population, soft loans and subsidies are allocated for the development of dekhkan farms and household plots.

3) Development

of modern

infrastructure. $\mathrm{H}$ and today carried out extensive work on the implementation of targeted programs to build affordable housing, development and modernization of road transport, engineering, communications and social infrastructure that serves to improve the living conditions of the population, both in cities and in villages.

As announced in 2020, over the next three years, 9.8 trillion soums will be allocated for the construction of roads, 4.8 trillion soums - for the laying of water supply networks, 18.2 trillion - for the construction of power grids, 1.2 trillion - for gas supply. This funding is several times more than in the last ten years. In 2021, it is planned to improve roads, water and electricity supply, irrigation networks in 33 regions that are lagging behind in development, and 970 makhallas with a difficult situation.

4) Ensuring the availability of education and medicine. The strategic goal in the development of preschool education for the coming years is to create the necessary conditions for full coverage of all children, both in large cities and in remote areas, villages and auls. In 2021, it is planned to increase 
the coverage of preschool education to 65 percent, and by the end of 2023 - to 75 percent. In collaboration with UNICEF and the World Bank, a model of early childhood education at home for children with disabilities will be launched.

In order to provide rural schools with qualified personnel and improve the quality of education, a special program is envisaged. It provides for a 50 percent salary increase for teachers who teach in a remote school in another area, and a 100 percent salary increase for those teaching in another area.

Starting in 2021, the number of state grants for higher education will be increased by at least 25 percent. The quota of scholarships for girls from low-income families will be doubled and brought to 2 thousand.

For a wider coverage of the population with primary health care institutions, in the next 3 years, it is planned to open 315 points of family doctors and 85 family polyclinics in the republic. The list of free medical services and medicines provided by the state will be revised, and a system of guaranteed provision of them to the population will be gradually established.

Also, within the framework of the Rural Doctor program, more than a thousand doctors working in remote areas will receive financial assistance in the amount of 30 million soums and will be provided with service housing.

\section{CONCLUSIONS}

In general, the introduction of new mechanisms and the adoption of important measures to support low-income groups of the population are evidence of a high degree of personal involvement of the President and government agencies at all levels in solving the problem of poverty. They show that the government is serious about improving the lives of people in every way, especially those who need support and find it difficult to get out of poverty on their own.

The measures taken to reduce poverty are systemic and long-term in nature, they are designed to obtain breakthrough positive results in the coming years, without postponing the solution of problems to the distant future. As the successful experience and achieved results of the PRC show, the tasks and goals that Uzbekistan faces today in terms of poverty reduction are quite achievable and solvable.

Acknowledgments. We are grateful to the scientists for their extensive coverage of the methods, relevance and importance of poor reduction. We thank the staff of the Ministry of Innovative Development of the Republic of Uzbekistan and the State Statistics Committee of the Republic of
Uzbekistan and the Ministry of Economic Development and Poverty Reduction of the Republic of Uzbekistan for their active assistance in this work.

\section{REFERENCES}

1. Olopade, B. C., Okodua, H., Oladosun, M., \& Asaleye, A. J. (2019). Human capital and poverty reduction in OPEC membercountries. Heliyon, 5(8). https://doi.org/10.1016/j.heliyon.2019.e02279

2. Magombeyi, M. T., \& Odhiambo, N. M. (2017). Foreign Direct Investment and Poverty Reduction. Comparative Economic Research, 20(2), 73-89. https://doi.org/10.1515/cer-2017-0013

3. Rewilak, J. (2017). The role of financial development in poverty reduction. Review of Development Finance, 7(2), 169-176. https://doi.org/10.1016/j.rdf.2017.10.001

4. Miyamoto, M. (2020). Poverty reduction saves forests sustainably: Lessons for deforestation policies. World Development, 127. https://doi.org/10.1016/j.worlddev.2019.104746

5. Liu, Q. Q., Yu, M., \& Wang, X. L. (2015). Poverty reduction within the framework of SDGs and Post-2015 Development Agenda. Advances in Climate Change Research, 6(1), 67-73. https://doi.org/10.1016/j.accre.2015.09.004

6. Ahmad, F., Draz, M. U., Su, L., Ozturk, I., Rauf, A., \& Ali, S. (2019). Impact of FDI inflows on poverty reduction in the ASEAN and SAARC economies. Sustainability (Switzerland), 11(9). https://doi.org/10.3390/su11092565

7. Durmanov, A., Umarov, S., Rakhimova, K., Khodjimukhamedova, S., Akhmedov, A., \& Mirzayev, S. (2021). Development of the organizational and economic mechanisms of greenhouse industry in the Republic of Uzbekistan. Journal of Environmental Management and Tourism, 12(2), 331-340. https://doi.org/10.14505//jemt.v12.2(50).03

8. S.Umarov Investment and Innovative Development $W$ ays of Water Resources. American Journal of Business, Economics and Management. 2016; 4(6): 170-174.

9. Nurimbetov, T., Umarov, S., Khafizova, Z., Bayjanov, S., Nazarbaev, O., Mirkurbanova, R., Durmanov, A. (2021). Optimization of the main parameters of the support-lump-breaking coil. Eastern-European Journal of Enterprise Technologies, 2 (1 (110)), 27-36. https://doi.org/10.15587/1729-4061.2021.229184

10. Nazarova F., Sangirova U., Abdurazakova N, Beknazarov Z. (2020). Development of human capital management at the transition to the digital economy of the republic of Uzbekistan. Solid State Technology, 63 (4), pp. 283-296.3.

11. Horbach L., Hilorme T., Nazarova F., Andriichenko N. (2020). Corporate Restructuring in the Coordinate of the Life Cycle Model. 35th IBIMA Conference: Sustainable Economic Development in Era Digitization, Seville, Spain. URL:https://ibima.org/accepted- 
paper/corporate-restructuring-in-the-coordinateof-the-life-cycle-model-2

12. Umarov S., Durmanov A., Li M., Khushvaktova K., Yakubova K., Shanasirova N. (2021). Features of the application of game theory in the tasks organizational and economic mechanisms greenhouse economy. Turkish Journal of Computer and Mathematics Education, 12 (11) pp. 3544-3550

13. Umarov S., Yusupov E., Yakubova S., Saipova M., Mamasadikov A., Khamrayeva S., Durmanov A. (2021). The cognitive model and its implementation of the enterprise Uzmobile. Turkish Journal of Computer and Mathematics Education, 12 (11) pp. 3479-3486

14. Turdieva M.U. (2020). Impact of covid-19 virus on tourism in Uzbekistan. Bulletin of Science and Education, 23 (101) pp. 32-34 